\title{
10 health stories that mattered: May 26-30
}

- Melanoma is one of the fastest rising cancers in Canada and people should better protect themselves from ultraviolet radiation, states a report released by the Canadian Cancer Society. Malignant melanoma is expected to cause 1050 deaths in Canada in 2014, and there will be an estimated 6500 new cases.

- Prime Minister Stephen Harper will attempt to keep the well-being of mothers and children on the global development agenda after Canada's funding commitments expire in 2015, he announced at a summit on maternal and child health in Toronto. Some nongovernmental organizations raised concerns, however, about the lack of funding for family planning and safe abortions.

- Cases of AIDS have decreased by more than $80 \%$ in British Columbia since 1996, according to Health Minister Terry Lake. The decrease prompted St. Paul's Hospital in Vancouver to repurpose a ward once used to treat patients dying from AIDS to now treat those living with HIV.

- The number of cases of measles in the Edmonton area has risen to 13 with no end in sight, say Alberta health officials, though the outbreak appears to have subsided in other areas of the province. About 10000 people in the region have received the measles vaccine in the past month.

- There were 11528 fewer patients in Saskatchewan waiting more than three months for surgery in March 2014 than in March 2010, a decrease of $75 \%$, the province's government announced. Most health regions are meeting or nearly meeting surgical wait-time goals, though the two largest health regions, Saskatoon and Regina, are lagging because of high demand for surgeries.

- About a third of hospital bed use in Ontario (more than 900000 days in hospital in 2011) could be attributed to smoking, physical inactivity, poor diet and unhealthy alcohol consumption, according to a report by the Institute for Clinical Evaluative Sciences. The researchers also created an online tool to estimate life expectancy and future hospital use based on health and lifestyle choices.

- Quebec must limit growth in health spending, among other reforms, to achieve a sustainable balanced budget, states a report by the Institut du Québec (full version in French only). Lowering the annual increase in health care spending from $5.2 \%$ to $4.2 \%$ would improve "budget prospects substantially," states the institute.

- Medical officers of health in New
Brunswick should have more independence to speak out on public health issues without political interference, according to the New Brunswick Medical Society. The call for increased autonomy comes after the provincial government showed reluctance to release a report by its chief medical officer of health about the health impacts of the shale gas industry.

- British Columbia residents using prescription heroin as part of a clinical trial have been granted a temporary injunction to continue getting the drug. Federal Health Minister Rona Ambrose announced last year that the federal government would be closing "loopholes" in a special access program that permitted certain people with drug addictions to receive heroin.

- The government of Prince Edward Island is not interested in providing abortion services in the province, reports CBC News. A proposal had been put forth to create a twicemonthly outpatient abortion clinic in PEI, the only province without abortion services, but Premier Robert Ghiz said the province will instead continue to pay for women to have the procedure in other provinces and that "the status quo is working." Roger Collier, CMAJ

CMAJ 2014. DOI:10.1503/cmaj.109-4824 